\title{
ANALISIS UJI MIKROBIOLOGI DAN LOGAM BERAT PADA SCRUB BERBAHAN DASAR KAPUR SIRIH
}

\author{
Nurul Fitria Apriliani ${ }^{1}$, Gading Wilda Aniriani ${ }^{2}$ \\ ${ }^{1}$ Program Studi Teknik Informatika Fakultas Teknik Universitas Islam Lamongan \\ ${ }^{2}$ Program Studi Teknik Sipil Fakultas Teknik Universitas Islam Lamongan \\ e-mail: nfitria.apriliani@gmail.com , gading.wildaa@gmail.com
}

\begin{abstract}
ABSTRAK
Kapur sirih dibuat dari pengolahan batu kapur hasil pembakaran yang direndam dalam air dalam waktu satu sampai dua minggu sampai hancur dan berbentuk seperti pasta. Kapur sirih ini pada zaman dahulu digunakan oleh para orang tua sebgai campuran ramuan untuk merawat gigi.sedangkan pada pengobatan-pengobatan tradisional juga digunakan sebagai obat mengatasi gusi bengkak,bisul,masalah haid serta penyakit kulit seperti menghilangkan jerawat, menghilangkan bau badan serta memutihkan ketiak. Atas dasar itulah penelitian ini menggunakan bahan dasar kapur sirih agar bisa digunakan sebagai alternatif pemanfaatan kapur sirih. Pembuatan scrub di buat dengan bahan dasar kapur sirih dicampur dengan bahan lain seperti beras, minyak zaitun, minyak lavender,metil paraben,dan air jeruk nipis. Scrub dibuat dengan variasi penambahan kapur sirih. Dari formulasi yang dibuat kemudian diamati yang paling bagus berdasarkan pengamatan organoleptik dan dilakukan beberapa uji. Uji mikrobiologi sampel menunjukkan bahwa hasil dari Uji Angka Lempeng Total sebesar 5,0 x $10^{5} \mathrm{Cfu} / \mathrm{g}$ dan Angka Kapang Khamir sebesar $1,6 \times 10^{4} \mathrm{Cfu} / \mathrm{g}$ tidak memenuhi persyaratan yang ditetapkan oleh BPOM. Sedangkan cemaran bakteri Staphylococcus aureus, Pseudomonas aeruginosa, Candida albicans serta cemaran logam berat $\mathrm{Pb}$ dan $\mathrm{Hg}$ adalah negatif.
\end{abstract}

Kata Kunci : Kapur sirih, Scrub dan Mikrobiologi

\section{ANALYSIS OF MICROBIOLOGY AND HEAVY METALS TEST IN SCRUB FROM LIME BETEL}

\begin{abstract}
Lime betel made from the processing of limestone combustion results are immersed in water within one to two weeks until destroyed and shaped like a paste. This Lime betel is used in the past by the parents sebgai mix of ingredients to treat teeth. While on traditional treatments are also used as a remedy to overcome swollen gums, boils, menstrual problems and skin diseases such as eliminating acne, eliminate body odor and whiten armpits. On that basis this research using the basic ingredients of Lime betel to be used as an alternative utilization of Lime betel . Preparation of scrubs made with basic ingredients of lime betel mixed with other ingredients such as rice, olive oil, lavender oil, methyl paraben, and lime juice. Scrub made with variations of addition of Lime betel. From the formulation made then the best observed based on organoleptic observation and conducted several tests. The sample microbiological test showed that the results from the Total Plate Numbers Test of 5.0 x 105 Cfu / g and the Kapang Khamir Figures of 1.6 x 104 Cfu / $\mathrm{g}$ did not meet the requirements set by BPOM. While bacterial contamination Staphylococcus aureus, Pseudomonas aeruginosa, Candida albicans and heavy metal contamination $\mathrm{Pb}$ and $\mathrm{Hg}$ is negative.
\end{abstract}

Keywords: Lime betel, Scrub,Microbiology

\section{PENDAHULUAN}

Kapur sirih merupakan produk olahan dari batu kapur maupun cangkang kerang yang dihancurkan kemudian dipanaskkan dan didiamkan beberapa hari. Batu kapur di 126 icroorga sangat banyak digunakan sebagai bahan bangunan, campuran semen dan bahan cat. Sedangkan di luar negeri batu kapur yang telah melalui 
proses presipitasi dapat digunakan sebagai campuran kosmetik, drug delivery, bahan bioaktif, hingga suplemen nutrisi. Kapur sirih sejak dulu oleh masyarakat digunakan untuk berbagai pengobatan tradisional berbagai penyakit. Untuk pengobatan herbal kapur sirih digunakan untuk mengobati penyakit encok, menhilangkan gatal pada tenggorokan atau mengeluarkan dahak, menyembuhkan sakit perut(Susiarti, 2006). Kapur sirih bisa digunakan sebagai obat bersamaan dengan bahan lain, seperti untuk mengatasi gusi bengkak, bisul (Setyowati,2010), masalah haid, digigit serangga serta penyakit kulit misalnya panu, kurap, dan kutil (Perpustakaan Negeri Malaysia, 2001). Kapur sirih atau kalsium hidroksida ini juga telah diuji dalam pengobatan radang pada pulpa anjing (Hendry et al, 2005). Aplikasi pada aspek kecantikan biasanya kapur sirih dipakai untuk menghilangkan jerawat, menghilangkan bau badan dan memutihkan ketiak (Sudirman,2010), memutihkan pangkal paha, dan merontokkan bulu.

Hal inilah yang melatarbelakangi untuk membuat ide pemanfaatan kapur sirih untuk produk perawatan kulit. Hal ini juga ditunjang oleh semakin besarnya kebutuhan dan permintaan pasar konsumen Indonesia akan produk produk kecantikan dan perawatan tubuh apalagi yang berbahan organik sehingga dapat meningkatkan nilai guna dan nilai ekonomis dari batu kapur.

Adapun tujuan dari penelitian ini adalah 1.Mendapatkan gamping scrub dari bahan dasar kapur sirih

2.Mengetahui proporsi komposisi yang tepat untuk scrub dari bahan utama kapur sirih dan beras yang efektif dan disukai

3. Mengetahui efektivitas gamping scrub sebagai produk perawatan tubuh untuk mencerahkan kulit

\section{METODE PENELITIAN}

Metode penelitian yang dilakukan pada penelitian ini adalah metode eksperimen uji coba rekayasa produk. Alat yang digunakan yaitu Timbangan, Blender, Pipet tetes, $\mathrm{pH}$ meter, gelas ukur, Pisau, perasan jeruk, kertas filter, baskom, pengaduk, Cawan petri. Sedangkan bahan yang digunakan yaitu Kapur sirih, Beras, Jeruk nipis, Minyak zaitun, dan Minyak essensial.

\section{Waktu dan Tempat penelitian}

Penelitian dilakukan di laboratorium Technopark Universitas Islam Lamongan pada Mei-Agustus 2017

\section{Pembuatan scrub}

Kapur sirih diperoleh dari pembakaran batu kapur atau batu gamping pada suhu tinggi kemudian di endapkan dengan cara di larutkan pada air dan didiamkan slama 7-8 hari. Hasil endapan yang berupa pasta di sisihkan kemudian dipanaskan sambil diaduk agar tidak ada lagi kapur yang bergumpal dan digunakan untuk langkah selanjutnya Beras di rendam dengan air selama 24 jam. Setelah semalam maka dikringkan kemudian haluskan dengan cara di blender dan diayak Jeruk nipis diperas kemudian airnya disaring dengan menggunakan kertas saring. Bahan pasta batu kapur sirih:pasta beras masing masing $1: 8,1: 4,1: 3,1: 2$, dan 1:1 dicampur dengan minyak zaitun dan minyak essensial yang dicampurkan lebih dulu agar mencegah bau tengik yang muncul. Setelah tercampur maka baru ditambahkan metil paraben sebagai pengawet kemudian perasan air jeruk nipis diaduk secara homogen. fungsinya adalah mengatur agar $\mathrm{pH}$ keasamaan formula lulur sesuai dengan $\mathrm{pH}$ kulit normal. Semua bahan dicampur dan di lakukan pengujian kemudian dianalisis dan ditarik kesimpulan.

\section{Analisis scrub}

Kelima sampel scrub dianalis is $\mathrm{pH}$ dengan kertas $\mathrm{pH}$ kemudian diamati organoleptik meliputi warna,tekstur dan kekentalan. Kemudian dari pengamatan organoleptik di ambil satu sampel yang dianggap terbaik dari ketiga unsur tersebut kemudian diuji kandungan mikroorganisme (Farmakope Indonesia V,1995 dan Prosedur Operasional Baku Pengujian Mikrobiologi PPOM) dan logam berat Timbal $(\mathrm{Pb})$ dan mercuri (Hg) (Metode AAS) di Unit Pengujian Farmasi Universitas Airlangga Surabaya.

\section{HASIL DAN PEMBAHASAN}

Kapur sirih serta bahan-bahan lain di formulasi dengan berbagai macam variasi persentase batu kapur sehingga menghasilkan formulasi yang disajikan dalam Tabel 1 . 
Tabel 1. Formula scrub dengan variasi

Penambahan banyaknya kapursirih

\begin{tabular}{|l|l|l|l|l|l|l|}
\hline $\begin{array}{l}\text { N } \\
\text { 0 }\end{array}$ & $\begin{array}{l}\text { Baha } \\
\text { n }\end{array}$ & $\begin{array}{l}\text { F 1 } \\
\mathbf{1 : 1}\end{array}$ & $\begin{array}{l}\text { F 2 } \\
\mathbf{1 : 2}\end{array}$ & $\begin{array}{l}\text { F 3 } \\
\mathbf{1 : 3}\end{array}$ & $\begin{array}{l}\text { F 4 } \\
\mathbf{1 : 4}\end{array}$ & $\begin{array}{l}\text { F 5 } \\
\mathbf{1 : 8}\end{array}$ \\
\hline 1 & $\begin{array}{l}\text { Kapur } \\
\text { sirih }\end{array}$ & $\begin{array}{l}40 \\
\text { gram }\end{array}$ & $\begin{array}{l}20 \\
\text { gram }\end{array}$ & $\begin{array}{l}13,3 \\
\text { gram }\end{array}$ & $\begin{array}{l}10 \\
\text { gram }\end{array}$ & $\begin{array}{l}5 \\
\text { gram }\end{array}$ \\
\hline 2 & $\begin{array}{l}\text { Tepug } \\
\text { beras }\end{array}$ & $\begin{array}{l}40 \\
\text { gram }\end{array}$ & $\begin{array}{l}40 \\
\text { gram }\end{array}$ & $\begin{array}{l}40 \\
\text { gram }\end{array}$ & $\begin{array}{l}40 \\
\text { gram }\end{array}$ & $\begin{array}{l}40 \\
\text { gram }\end{array}$ \\
\hline 3 & $\begin{array}{l}\text { Minyk } \\
\text { zaitun }\end{array}$ & $3 \mathrm{ml}$ & $3 \mathrm{ml}$ & $3 \mathrm{ml}$ & $3 \mathrm{ml}$ & $3 \mathrm{ml}$ \\
\hline 4 & $\begin{array}{l}\text { Laven } \\
\text { der oil }\end{array}$ & $2 \mathrm{ml}$ & $2 \mathrm{ml}$ & $2 \mathrm{ml}$ & $2 \mathrm{ml}$ & $2 \mathrm{ml}$ \\
\hline 5 & $\begin{array}{l}\text { Metil } \\
\text { parab } \\
\text { n }\end{array}$ & $\begin{array}{l}0,2 \\
\text { gram }\end{array}$ & $\begin{array}{l}0,2 \\
\text { gram }\end{array}$ & $\begin{array}{l}0,2 \\
\text { gram }\end{array}$ & $\begin{array}{l}0,2 \\
\text { gram }\end{array}$ & $\begin{array}{l}0,2 \\
\text { gram }\end{array}$ \\
\hline 6 & $\begin{array}{l}\text { Air } \\
\text { jeruk } \\
\text { nipis }\end{array}$ & $\begin{array}{l}\text { Ad } \\
100 \\
\text { gram }\end{array}$ & $\begin{array}{l}\text { Ad100 } \\
\text { gram }\end{array}$ & $\begin{array}{l}\text { Ad } \\
100 \\
\text { gram }\end{array}$ & $\begin{array}{l}\text { Ad } \\
100 \\
\text { gram }\end{array}$ & $\begin{array}{l}\text { Ad } \\
100 \\
\text { gram }\end{array}$ \\
\hline
\end{tabular}

Formulasi tersebut kemudian dievaluasi dengan beberrapa pengujian. Secara sederhana dilakukan pengamatan organoleptis meliputi parameter warna, tekstur dan kekentalan dari masing-masing formulasi (Tabel 2).

Tabel 2. Hasil pengamatan organoleptis

\begin{tabular}{|c|c|c|c|c|c|}
\hline \multirow{2}{*}{$\begin{array}{c}\text { Parame } \\
\text { ter }\end{array}$} & \multicolumn{5}{|c|}{ Formulasi } \\
\hline & F1 & F2 & F3 & F4 & F5 \\
\hline Warna & $\begin{array}{l}\text { Putih } \\
\text { kekun } \\
\text { ingan }\end{array}$ & $\begin{array}{l}\text { Kunin } \\
\mathrm{g}\end{array}$ & Putih & $\begin{array}{l}\text { Putih } \\
\text { kekunin } \\
\text { gan }\end{array}$ & Putih \\
\hline Tekstur & Padat & Padat & Lembek & Lembek & $\begin{array}{l}\text { Sangat } \\
\text { Lembek }\end{array}$ \\
\hline $\begin{array}{l}\text { Kekenta } \\
\text { lan }\end{array}$ & $\begin{array}{l}\text { Sanga } \\
\mathrm{t} \\
\text { Kenta } \\
1\end{array}$ & Kental & $\begin{array}{l}\text { Cukup } \\
\text { Kental }\end{array}$ & $\begin{array}{l}\text { Cukup } \\
\text { Kental }\end{array}$ & Encer \\
\hline
\end{tabular}

Syarat mutu sediaan untuk kulit memiliki beberapa standart yang telah ditetapkan dalam SNI agar aman digunakan.Hasilnya disajikan dalam Tabel 3.

Tabel 3 .Hasil Uji nilai pH scrub

\begin{tabular}{|c|c|}
\hline Formula Scrub & pH \\
\hline Formula 1 & 12 \\
\hline Formula 2 & 5 \\
\hline Formula 3 & 5 \\
\hline Formula 4 & 5 \\
\hline Formula 5 & 3 \\
\hline
\end{tabular}

Salah satu komponen yang penting dilakukan adalah pengujian derajat keasaman atau pH. Kadar keasaman untuk produk kosmetik atau produk yang digunakan untuk pemakaian luar yang berhubungan langsung dengan kullit harus sesuai dengan $\mathrm{pH}$ keseimbangan kulit.hal ini agar tidak terjadi iritasi pada kulit akibat penggunaan bahan dengan $\mathrm{pH}$ terlalu asam dan akan mengakibatkan kulit bersisik jika pHnya terlalu basa. Fisiologi kulit normal mempunyai $\mathrm{pH}$ tertentu yaitu sekitar 4,56,5(And iris nanti,2012). Was itaatmadja(1997) menjelaskan bahwa produk kosmetik sebaiknya memiliki pH sekitar 5,5 sedangkan menurut SNI 16-4399-1996 mensyaratkan produk krim kulit memiliki $\mathrm{pH}$ antara 4,58,0. Berdasarkan hasil percobaan pada formula 1 diketahui $\mathrm{pH}$ sangat basa dikarenakan komposisi kapur sirih yang sangat banyak sehingga air jeruk nipis tidak mampu menurunkan derajat keasamannya. Pada formula 2,3 dan 4 menghasilkan nilai pH 5,sehingga dari ketiga formula ini memenuhi syarat untuk diaplikasikan ke kulit. Formula 5 yaitu dengan komposisi perbandingan 1:8 menghasilkan $\mathrm{pH} 3$, hal ini dikarenakan kandungan kapur sirih yang sangat sedikit. Dari semua formula yang dibuat dapat dilihat bahwa semuanya menghasilkan formulasi yang masih bisa diterima oleh kulit normal kecuali pada perbandingan 1:1 dan 1:8.

Tabel4. Hasil uji mikrobiologi dan uji cemaran logam berat pada $s c r u b$ dengan perbandingan 1:4 (Formula 4)

\begin{tabular}{|l|c|c|}
\hline No & $\begin{array}{c}\text { Jenis } \\
\text { pemeriksaan }\end{array}$ & Hasil \\
\hline 1. & $\begin{array}{c}\text { Angka Lempeng } \\
\text { total }(\mathrm{Cfu} / \mathrm{g})\end{array}$ & $5,0 \times 10^{5}$ \\
\hline 2. & $\begin{array}{c}\text { Angka } \mathrm{kapang} \\
\text { khamir(Cfu/g) }\end{array}$ & $1,6 \times 10^{4}$ \\
\hline 3. & $\begin{array}{c}\text { Staphylococcus } \\
\text { aureus } \text { (Cfu/g) }\end{array}$ & negatif \\
\hline 4. & $\begin{array}{c}\text { Pseudomonas } \\
\text { aeruginosa }(\mathrm{Cfu} / \mathrm{g})\end{array}$ & negatif \\
\hline 5. & $\begin{array}{c}\text { Eschrichia coli } \\
\text { (Cfu/g) }\end{array}$ & negatif \\
\hline 6. & $\begin{array}{c}\text { Salmonella } \\
\text { sp }(\mathrm{Cfu} / \mathrm{g})\end{array}$ & negatif \\
\hline 7. & $\begin{array}{c}\text { Candida albicans } \\
\text { (Cfu/g) }\end{array}$ & negatif \\
\hline 8. & Timbal $(\mathrm{Pb})$ & negatif \\
\hline 9. & Merkuri (Hg) & negatif \\
\hline
\end{tabular}

Analisis mutu scrub salah satunya dilakukan dengan melakukan pengujian mikrobiologi dan cemaran logam berat. Sampel yang diuji hanya formula 4 dengan perbandingan 1:4 dilihat dari hasil pengamatan organoleptik yang dinilai paling 
bagus.Pengujian ini merupakan salah satu pengujian wajib dari BPOM. Pengujian mikrobiologi meliputi pengujian Angka Lempeng Total (ALT), Angka Kapang Khamir (AKK) dan pengujian terhadap beberapa bakteri. Angka lempeng total merupakan pengujian kuantitatif untuk mengetahui jumlah mikroba yang ada pada suatu sampel. ALT dapat digunakan sebagai indikator higienitas produk, analis is mikroba lingkungan pada produk jadi, indikator proses pengawasan dan dapat digunakan sebagai dasar kecurigaan dapat atau tidak diterimanya suatu produk berdasarkan kualitas mikrobiologinya. Sedangkan pengujian Angka Kapang Khamir pada prinsipnya menghitung cemaran fungi agar tidak melebihi batas yang ditetapkan. Khamir adalah kelompok fungi uniseluler yang bersifat mikroskopik yang dapat menimbulkan patogen pada manusia sedangkan kapang adalah fungi multiseluler yang mempunyai filamen yang dapat juga bersifat toksin.

Peraturan kepala BPOM Nomor 17 tahun 2014 tentang perubahan atas peraturan kepala BPOM No.HK.03.1.23.07.11.6662 tahun 2011 tentang persyaratan cemaran mikroba dan logam berat dalam kosmetika menyatakan bahwa persyaratan cemaran mikroba kosmetik selain untuk anak dibawah 3 tahun, area di sekitar mata dan membran mukosa bahwa Angka Lempeng Total dan Angka Kapang Khamir tidak lebih dari $10^{3}$ Koloni/g, bakteri Staphylococcus aureus, Pseudomonas aeruginosa, Candida albicans negatif per0,1 g atau $0,1 \mathrm{ml}$ sampel uji. sedangkan untuk persyaratan cemaran logam berat merkuri $(\mathrm{Hg})$ yaitu tidak lebih dari 1 $\mathrm{mg} / \mathrm{kg}$ atau $1 \mathrm{mg} / \mathrm{L}$ sedangkan timbal $(\mathrm{Pb})$ tidak boleh lebih dari $20 \mathrm{mg} / \mathrm{kg}$ atau $20 \mathrm{mg} / \mathrm{L}$

Hasil pengujian Angka Lempeng Total menunjukkan jumlah mikroba pada sampel sebesar 5,0 x $10^{5} \mathrm{Cfu} / \mathrm{g}$. Sedangkan pengujian Angka Kaping Khamir menghasilkan angka $1,6 \quad$ x $10^{4} \quad \mathrm{Cfu} / \mathrm{g}$. Tingginya nilai tersebut yang tidak memenuhi persyaratan cemaran mikroba oleh BPOM dimungkinan karena beberapa hal,yaitu salah satunya dari bahan scrub itu sendiri. Perendaman beras dengan aquadest yang digunakan sebagai campuran scrub memungkinan terkontaminasi dengan mikroba. Hal ini tentu saja karena jika tidak mengontrol dengan tepat maka beras akan mnjadi busuk atau tengik selama proses perendaman yang tentu mnjadi sumber pertumbuhan bakteri. Selain itu penggunaan bahan air jeruk nipis yang sangat mudah basi juga akan mempengaruhi pertumbuhan mikroba sampai dengan waktu pengujian berakhir.

Peran metilparaben sebagai pengawet tidak berfungsi maksimal dimungkinkan karena kosentrasi metil paraben yang diberikan relatif sedikit dan metil paraben tidak bisa larut dalam air produk jadi scrub. Seperti diketahui bahwa metilparaben mudah larut pada air panas dengan suhu $80 \mathrm{C}$ (Rowe et al,1999 dalam Andiristanti 2012). Selain itu metil paraben mempunyai kelemahan yaitu kurang efektif terhad ap bakteri gram negatif (Idson\&Lazarus,1994 dalam Yumas dkk 2015). Walaupun jumlah total mikroba masih menunjukkan angka yang relatif besar tetapi jenis Staphylococcus aureus, Pseudomonas aeruginosa, Candida albicans tidak ditemukan dalam produk scrub.

Tabel 4 juga menunjukkan bahwa kandungan logam berat $\mathrm{Pb}$ dan $\mathrm{Hg}$ pada produk sampel tidak ditemukan atau negatif. Hal ini dikarenakan bahan bahan yang dipakai dalam pembuatan scrub sebagian besar adalah bahan alami sehingga aman digunakan. salah satu dampak yang ditimbulkan jika produk kosmetik mengandung logam berat yaitu kulit akan menjadi ruam dan mengalami perubahan warna,bintik hitam pada kulit,alergi,iritasi kulit dan jika digunakan dalam waktu yang lama akan membahayakan bagi kesehatan seperti dalam Peraturan Menteri Kesehatan RI No.445/MENKES/PER/V/1998 tentang bahan,zat warna,substrat,zat pengawet dan tabir surya pada kosmetik.

\section{KESIMPULAN DAN SARAN}

\section{Kesimpulan}

Kesimpulan yang dapat diambil dari penelitian ini adalah:

1. Kapur sirih dapat diformulasikan sebagai sediaan scrub yang dibuat dengan lima variasi yaitu perbandingan kapur sirih:tepung beras 1:1, 1:2, 1:3, 1:4 dan 1:8 dan ditambahkan bahan tambahan lain yaitu minyak zaitun, minyak essensial dan jeruk nipis. 
2. Melalui pengamatan organoleptik diketahui formula dengan perbandingan 1:4 mempunyai hasil yang paling bagus dari penilaian warna,tekstur dan kekentalan.

3. Hasil dari pengujian terhadap beberapa variabel yaitu $\mathrm{pH}$ menunjukkan bahwa $\mathrm{pH}$ formula yang masih masuk dalam batas yang disyaratkan adalah pada formula 2,3 dan 4. Sedangkan hasil uji mikrobiologi pada scrub menunjukkan bahwa Angka Lempeng Total dan Angka Kapang Khamir belum memenuhi standart BPOM karena jumlah mikroba dan jamur masih cukup tinggi, tetapi pada pengujian cemaran logam dapat diketahui bahwa logam negatif mengandung $\mathrm{Hg}$ dan $\mathrm{Pb}$

\section{Saran}

Saran yang dapat diberikan dari penelitian ini adalah

1. Diperlukan evaluasi tentang bahan scrub serta proses pembuatannya dikarenakan hal ini diduga sangat berpengaruh terhadap cemaran mikroba dalam hasil jadi scrub agar jumlah total mikroba dan jamur dapat memenuhi yang disyaratkan oleh BPOM.

2. Masih diperlukan banyak pengujian pendukung tentang standard kosmetik yang baik dan memenuhi persyaratan.

\section{DAFTAR PUSTAKA}

Andirisnanti. 2012. Uji manfaat ekstrak kolagen kasar dari teripang Stichopus hermanni sebagai bahan pelembab kulit. Tesis: Fakultas Matematika dan Pengetahuan Alam Program Magister Herbal. Universitas Indonesia, Jakarta.

Hendry, John A., Jeansonne, Billie G., Dummett, Clifton O., dan Burrell, William. 2005. Comparison of Calcium Hydroxide and Zinc Oxide and Eugenol Pulpectomies in Primary Teeth of Dogs. Oral Patology Vol 54.

Setyowati, Francisca Murti. 2010. Etnofarmakologi Dan Pemakaian Tanaman Obat Suku Dayak Tunjung Di Kalimantan Timur. Media Litbang Kesehatan Vol. XX No.3, hal 104-112.
Sudirman. 2010. Pemanfaatan kapur sirih sebagai deodorant alternative pencegah terjadinya bau badan (PKM AI). Fakultas Ilmu pendidikan Universitas Negeri Malang, Malang.

Sutiarti, S. 2006. Pengetahuan Dan Pemanfaatan Tumbuhan Obat Di Sabang - Pulau Weh, Nangroe Aceh Darussalam. ISSN 1441-318X, Hal 198-209 ,Jakarta Juli 2006.

Wasitaatmadja,S.M.1997. Penuntun Ilmu Kosmetik Medik.Jakarta:Penerbit Universitas Indonesia

Yumas,dkk. 2015. Formulasi lulur krim dari bubuk kakao non fermentasi dan efek terhadap kulit. Jurnal Biopropal Industry Vol 6 No 2 Desember 2015 : 63-72.

Perpustakaan Negeri Malaysia. 2001. Sirih Pinang.Fromhttp://www.pnm.my/sirih pinang/sp-kapur.htm., 10 Juni 2011. 